\title{
ANALISIS PERUBAHAN SUDUT BLADE FAN COOLING TOWER TERHADAP PERFORMANCE COOLING TOWER UNIT 3 DI PT.X.
}

\author{
Harwan Ahyadi ${ }^{1}$, Achmad Kurnia Aldy ${ }^{2}$ \\ Program Studi Teknik Mesin S1, Institut Sains dan Teknologi Nasional ${ }^{12}$ \\ email $^{1}$ : harwanfti@yahoo.co.id
}

\begin{abstract}
Abstrak
Cooling Tower adalah alat yang digunakan untuk menurunkan suhu aliran air dengan cara mengekstraksi panas dari air dan mengemisikanya ke atmosfer. Jenis cooling tower yang dipergunakan pada unit 3 PLTP PT.X adalah Induced draft cooling tower Oleh karena itu dalam sebuah sistem pendingin perlu adanya sebuah evaluasi kinerja dari sebuah alat pendingin, penelitian yang dilakukan adalah analisis terhadap perubahan pada sudut blade fan cooling tower terhadap performance cooling tower. Dalam data spesifikasi cooling tower sebelum dilakukan perubahan sudut, maka didapat range sebesar $19,07^{\circ} \mathrm{C}$, approach sebesar $11,3^{\circ} \mathrm{C}$, dan efisiensi sebesar $69,4 \%$, evaporation loss sebesar 347,60 $\mathrm{m}^{3} / \mathrm{jam}$, drift loss sebesar $630,78 \mathrm{~m}^{3} / \mathrm{jam}$, windage loss sebesar 2.523,14 $\mathrm{m}^{3} / \mathrm{jam}$, make up water sebesar $3.532,51 \mathrm{~m}^{3} / \mathrm{jam}$. Hasil analisis memperoleh range sebesar $19,10^{\circ} \mathrm{C}$, approach sebesar $10,8^{\circ} \mathrm{C}$, dan efisiensi sebesar $72,27 \%$, evaporation loss sebesar 348,70 $\mathrm{m}^{3} / \mathrm{jam}$, drift loss sebesar $580,20 \mathrm{~m}^{3} / \mathrm{jam}$, windage loss sebesar $2.374,71 \mathrm{~m}^{3} / \mathrm{jam}$, make up water sebesar $3.312,94 \mathrm{~m}^{3} / \mathrm{jam}$. Dari hasil analisis maka didapat kesimpulan perubahan sudut fan blade cooling tower mempengaruhi nilai range, approach, efisiensi dan kerugian aliran cooling tower.
\end{abstract}

Kata kunci: Cooling Tower, Inducted Draft, Range, Approach, Efisiensi

\section{PENDAHULUAN}

Cooling tower atau menara pendingin merupakan peralatan yang digunakan untuk menurunkan suhu aliran air dengan cara mengekstraksi panas dari air dan mengemisikan panas ke atmosfer. Cooling tower yang digunakan pada permasalahan ini adalah cooling tower yang terdapat pada unit 3 PLTP PT.X didaerah Kamojang, Bandung.

Sistem pendingin harus dirancang mampu memenuhi kebutuhan operasi unit pembangkit secara berkelanjutan, ekonomis dan handal .Sistem pendingin di PLTP PT.X merupakan sistem pendingin dengan sirkulasi terbuka dari air hasil kondensasi uap, dimana kelebihan kondensat yang terjadi direinjeksi ke dalam sumur reinjeksi. Jenis cooling tower yang digunakan oleh PLTP PT.X adalah jenis Induced draft cross flow, prinsip penyerapan energi panas dari air yang disirkulasikan adalah dengan mengalirkan udara pendingin secara paksa dengan arah aliran tegak lurus menggunakan 5 fan cooling tower.

Dalam sebuah sistem pendingin perlu adanya sebuah evaluasi kinerja dari sebuah alat pendingin, Penelitian yang akan dilakukan adalah memberikan analisis terhadap perubahan pada sudut blade fan cooling tower terhadap performance cooling tower. Beberapa faktornya yaitu faktor debit yang masuk ,suhu masuk , suhu keluar, efisiensi , kerugian dan suhu lingkungan sekitar. Hal ini harus dianalisis sehingga dapat dilakukan evaluasi pada cooling tower.

Evaluasi yang dilakukan pada PLTP PT.X adalah melalukan program penghematan common energy atau energi yang digunakan untuk pemakaian sendiri pada PLTP PT.X, tujuannya untuk menghemat dari energi listrik yang digunakan pada PLTP PT.X dan lebih banyak energi yang didistribusikan untuk dijual, salah satunya adalah menghemat penggunaan motor listrik pada setiap komponen sistem pendingin pada motor listrik yang terdapat pada fan cooling tower. Dengan mengubah sudut blade fan cooling tower diharapkan adanya perubahan dalam penghematan penggunaan motor listrik. 


\section{TINJAUAN PUSTAKA}

\section{Cooling Tower Unit 3 Pada PT. X}

Cooling Tower atau menara pendingin adalah alat yang digunakan untuk menurunkan suhu aliran air dengan cara mengekstraksi panas dari air dan mengemisikanya ke atmosfer. Dengan demikian air yang tersisa didinginkan secara signifikan. Menara pendingin mampu suhu air lebih dari peralatan yang hanya menggunakan udara untuk membuang panas, seperti radiator dalam mobil, dan oleh karena itu biayanya lebih efektif dan efesien energinya.

Jenis cooling tower yang dipergunakan pada unit PLTP PT.X adalah Induced draft cooling tower dengan material utama konstruksinya adalah kayu yang telah diawetkan, selain kayu material lain biasanya berupa beton. Pada jenis ini udara masuk melalui sisi kisi menara yang cukup besar dan bergerak melalui fill. Fan blade dipasang dipuncak menara, dan dari puncak menara tersebut dibuang udara panas dan lembab ke udara bebas.

\section{Cooling Tower}

Bagian ini menjelaskan tentang bagaimana kinerja tenaga pendinginan dapat dikaji. Kinerja cooling tower di evaluasi untuk mengkaji tingkat approach dan range saat ini terhadap nilai desain, mengidentifikasi area terjadinya pemborosan energi dan memberikan saran perbaikan. Selama evaluasi kinerja, peralatan pemantauan yang portable digunakan untuk mengukur parameter-parameter berikut :

1. Temperatur udara wet bulb

2. Temperatur udara dry blub

3. Temperatur air masuk menara pendingin

4. Temperatur air keluar menara pendingin

5. Temperatur udara keluar

6. Pembacaan listrik motor pompa dan fan

7. Laju alir air

8. Laju alir udara

Range dan approach temperature dapat dilihat seperti pada

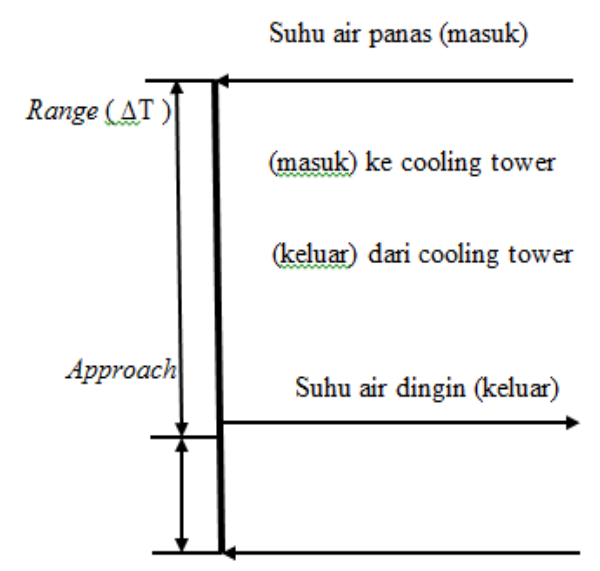

Gambar 1. Range dan Approach Temperature

Parameter terukur tersebut kemudian digunakan untuk menentukan kinerja cooling tower dengan beberapa cara, yaitu :

\section{Range}

Ini merupakan perbedaan antara temperatur air masuk dan keluar cooling tower. Range cooling tower yang tinggi berarti bahwa cooling tower telah mampu menurunkan temoeratur air secara efektif, dan kinerjanya bagus. Untuk mengetahui nilai range cooling tower ini, harus mengetahui terlebih dahulu nilai dari temperatur air masuk ( $\left.\mathrm{T}_{\text {in }}\right)$ dan temperatur air keluar $\left(\mathrm{T}_{\text {out }}\right)$. Temperatur air masuk $\left(\mathrm{T}_{\text {in }}\right)$ dan temperatur air keluar $\left(\mathrm{T}_{\text {out }}\right)$ ini memiliki nilai batasan. Untuk temperatur air masuk $\left(\mathrm{T}_{\text {in }}\right)$ memiliki suhu ideal antara $40^{\circ} \mathrm{C}-55^{\circ} \mathrm{C}$, temperatur air menurunkan temperatur air secara efektif, dan kinerjanya bagus. U masuk $\left(\mathrm{T}_{\text {in }}\right)$ ini tidak boleh kurang dari $40^{\circ} \mathrm{C}$ dan juga tidak boleh lebih dari $55^{\circ} \mathrm{C}$.

Karena apabila suhu air masuk kurang dari $40^{\circ} \mathrm{C}$, maka akan mengakibatkan suhu air menjadi kurang panas yang akan menyebabkan berkurangnya uap yang akan dihasilkan oleh PLTP.

Sedangkan jika temperatur air masuk $\left(\mathrm{T}_{\text {in }}\right)$ ini melebihi $55^{\circ} \mathrm{C}$ maka akan mengakibatkan suhu air menjadi sangat panas, yang akan menyebabkan pipa uap bocor karena terlalu banyak uap yang diproduksi. Dan untuk temperatur air keluar $\left(\mathrm{T}_{\text {out }}\right)$ memiliki suhu ideal antara $26 \mathrm{C}-30^{\circ} \mathrm{C}$. Temperatur air keluar $\left(\mathrm{T}_{\text {out }}\right)$ ini tidak boleh kurang dari $26^{\circ} \mathrm{C}$, karena akan mengalkibatkan suhu air menjadi terlalu dingin. Sedangkan jika temperatur - $:$ - 1...... i melebihi $30^{\circ} \mathrm{C}$ maka akan mє Gambar 2.17 Range dan $A p$ 
air menjadi hangat, yang akan menyebabkan sistem pendingin tidak bekerja optimal. .Untuk menghitung range cooling tower dapat menggunakan persamaan 2.1.

Range $\mathrm{CT}=\left[\mathrm{T}_{\text {in }}-\mathrm{T}_{\text {out }}\right]$

Dimana

Range $\mathrm{CT}=$ Range cooling tower $\left({ }^{\circ} \mathrm{C}\right)$

Tin=Temperatur masuk cooling tower $\left({ }^{\circ} \mathrm{C}\right)$

Tout=Temperatur keluar cooling tower $\left({ }^{\circ} \mathrm{C}\right)$

\section{Approach}

Merupakan perbedaan antara temperatur air dingin keluar cooling tower wet bulb. Semakin rendah approach semakin baik kinerja cooling dan approach harus dipantau, approach merupakan indicator yang lebih baik untuk kinerja cooling tower. Untuk menghitung approach cooling tower dapat menggunakan persamaan 2.2.

Approach CT $=[$ Tout $-\mathrm{Twb}]$

Dimana :

Approach CT =Approach cooling tower $\left({ }^{\circ} \mathrm{C}\right)$ $\mathrm{Twb}=$ Temperatur wet bulb cooling tower $\left({ }^{\circ} \mathrm{C}\right)$

\section{Efektifitas}

Merupakan perbandingan antara range dan range ideal (dalam persentase), yaitu perbedaan antara temperatur masuk air pendingin dan temperatur wet bulb ambien, atau dengan kata lain adalah $=$ Range $/($ Range + Approach $)$. Semakin tinggi perbandingan ini, maka semakin tinggi efektifitas menara pendingin. Untuk menghitung efektivitas cooling tower dapat menggunakan persamaan 2.3

Efektifitas Cooling Tower (\%) =

$$
\left.100 \% \times \frac{T_{\text {in }}-T_{\text {out }}}{\left(T_{\text {in }}-T_{\text {out }}\right)+\left(T_{\text {out }}-T_{\text {wb }}\right)}\right)
$$

\section{Drift Loss}

Nilai drift loss dari cooling tower PLTP PT.X sebagaimana diketahui dari tabel spesifikasi sebesar 0,05 \% dari sirkulasi air yang masuk kedalam cooling tower. Untuk menghitung kapasitas pendingin pada cooling tower dapat menggunakan persamaan 2.4

$\mathrm{D}=0,05 \times \mathrm{C}$
Merupakan jumlah air yang diuapkan agar terjadi pendinginan. Jumlah air yang menguap dipengaruhi oleh panas laten air itu sendiri. Apabila semakin besar jumlah kalor yang diserap oleh cooling tower maka semakin besar juga kehilangan penguapannya. Begitupun sebaliknya, semakin sedikit jumlah kalor cooling tower maka akan sedikit juga kehilangan penguapanya. Hal ini disebabkan oleh faktor dari suhu lingkungan, dimana apabila pada pagi hari kehilangan penguapan pada yang kecil. Tapi apabila pada siang hari, tower memiliki nilai yang tinggi. Untuk menghitung rugi penguapan tower dapat menggunakan persamaan 2.5

Rugi Penguapan (m3/jam)

$W e=0,00085 \times m_{c t} \times 1,8 \times\left(T_{\text {in }}-T_{\text {out }}\right)$ (2.5)

\section{Windage Loss}

Windage loss adalah kerugian penguapan akibat adanya angin disekeliling menara pendingin.

Diketahui bahwa ketentuan perhitungan untuk windage looses adalah:

$\mathrm{W}=0.1$ sampai $0.3 \%$ dari $\mathrm{C}$ untuk induced draft $\mathrm{W}=\mathrm{C} \times 0,2$.

\section{Make Up Water}

Jumlah make up water yang dibutuhkan dihitung berdasarkan neraca massa cooling tower

$\mathrm{M}=\mathrm{E}+\mathrm{D}+\mathrm{W}$

\section{METODOLOGI PENELITIAN}

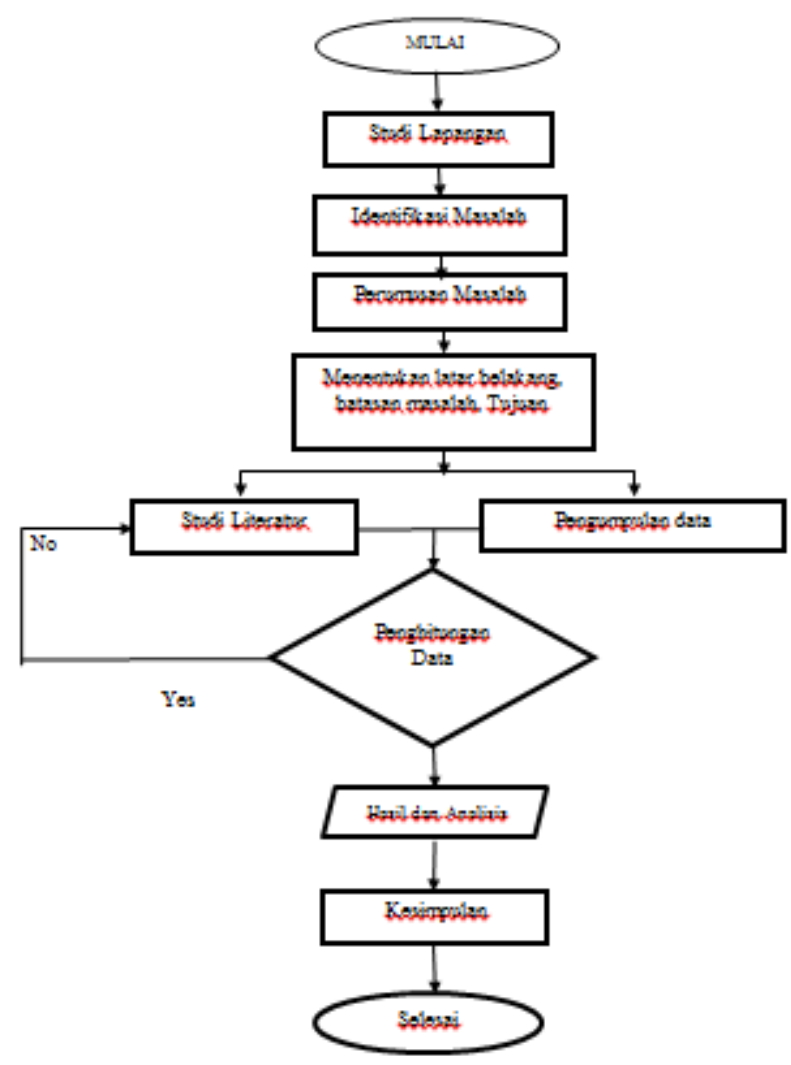

Gambar 2. Diagram alir penelitian 


\section{Spesifikasi Data}

Data yang diperlukan untuk menganalisis kinerja cooling tower yaitu data design dan data aktual data design sudah terlampir pada table 3.1 spesifikasi thermal cooling tower. Data aktual yang diambil adalah sebagai berikut yang terlampir pada tabel berikut.

Tabel 1. Data Desain dan Aktual

\begin{tabular}{|c|c|c|}
\hline keterangan & desain & Aktual \\
\hline Debit & $12.960 \mathrm{~m}^{3} / \mathrm{jam}$ & $13.100 \mathrm{~m}^{3 / \mathrm{jam}}$ \\
\hline Temperatur air masuk & $42,8^{\circ} \mathrm{C}$ & $49{ }^{\circ} \mathrm{C}$ \\
\hline Temperatur air keluar & $27^{\circ} \mathrm{C}$ & $30^{\circ} \mathrm{C}$ \\
\hline Temperatur wet bulb ambient & $18,5^{\circ} \mathrm{C}$ & $20^{\circ} \mathrm{C}$ \\
\hline Range & $16^{\circ} \mathrm{C}$ & $19^{\circ} \mathrm{C}$ \\
\hline Approach & $8,5^{\circ} \mathrm{C}$ & $10^{\circ} \mathrm{C}$ \\
\hline
\end{tabular}

\section{Perhitungan Efektifitas Cooling Tower}

Diketahui :

Tin $=53,6^{\circ} \mathrm{C}$

Tout $=31,3^{\circ} \mathrm{C}$

Twb $=25^{\circ} \mathrm{C}$

Penyelesaian :

$$
\begin{array}{ll}
\text { 1. Range }\left({ }^{\circ} \mathrm{C}\right) & =\left(\operatorname{Tin}^{\circ} \mathrm{C}-\operatorname{Tout}^{\circ} \mathrm{C}\right) \\
& =(53,6-31,3) \\
& =22,3{ }^{\circ} \mathrm{C} \\
\text { 2. Approach }\left({ }^{\circ} \mathrm{C}\right) & =\left(\text { Tout }^{\circ} \mathrm{C}-\operatorname{Twb}^{\circ} \mathrm{C}\right) \\
& =(31,3-25) \\
\text { 3. Efektifitas } & =6,3{ }^{\circ} \mathrm{C} \\
& =100 \% \times \frac{T_{\text {in }}-T_{\text {out }}}{\left(T_{\text {in }}-T_{\text {out }}\right)+\left(T_{\text {out }}-T_{\text {wb }}\right)} \\
& =100 \% \times \frac{\text { Range }}{(\text { Range }+ \text { Approach })} \\
& =100 \% \times \frac{22,3}{(22,3+6,3)} \\
& =77,97 \%
\end{array}
$$

\footnotetext{
Perhitungan Kerugian Aliran Pada cooling Tower Evaporation loss

$\mathrm{E}=0,00085 \times 1,8 \times \mathrm{C} \times \mathrm{R}$

$\mathrm{E}=0,00085 \times 1,8 \times 13.100 \times 19$

$\mathrm{E}=380,817 \mathrm{~m}^{3} / \mathrm{jam}$
}

\section{Drift loss}

$\mathrm{D}=0,05 \times \mathrm{C}$

$\mathrm{D}=0,05 \times 13.100=655 \mathrm{~m}^{3} / \mathrm{jam}$

Windage Loss

$\mathrm{W}=0,2 \times \mathrm{C}=0,2 \times 13.100=2620 \mathrm{~m}^{3} / \mathrm{jam}$

\section{Make Up water}

$\mathrm{M}=\mathrm{E}+\mathrm{D}+\mathrm{W}$

$M=380,817+655+2620=3.655,871 \mathrm{~m}^{3} / \mathrm{jam}$

\section{PEMBAHASAN}

\section{Range}

Nilai perhitungan perbedaan antara temperatur air masuk dan keluar cooling tower dari tahun 2016, 2017 dan 2018 tersaji pada grafik 3

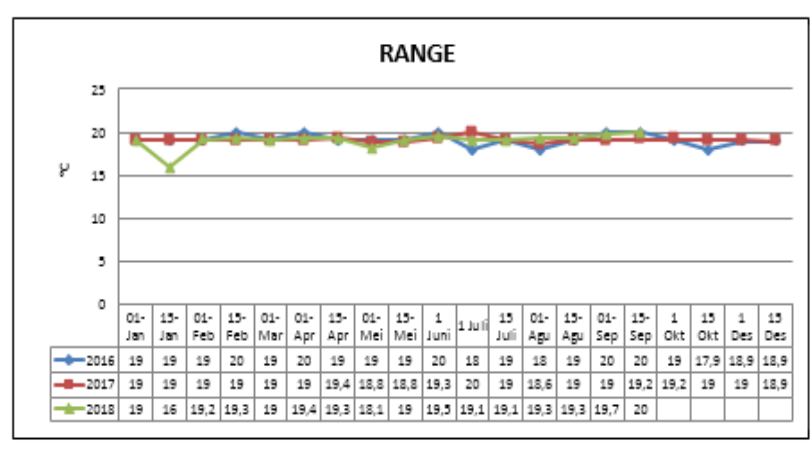

Gambar 3. Grafik Range

Jika dilihat pada gambar 3 Dari tahun 2016 sampai bulan maret 2018 sudut pada fan cooling tower unit 5 memiliki nilai 8,13 ${ }^{\circ}$ setelah bulan maret dirubah sudutnya menjadi $7,50^{\circ}$ dan rata-rata nilai range pada pahun 2016 sebesar 19,085 dan pada tahun 2017 sebesar 19,06 dan pada tahun 2018 sebesar 19,10

\section{Approach}

Nilai perhitungan perbedaan antara temperatur air dingin keluar cooling tower wet bulb. (approach) disajiakan dalam grafik 4

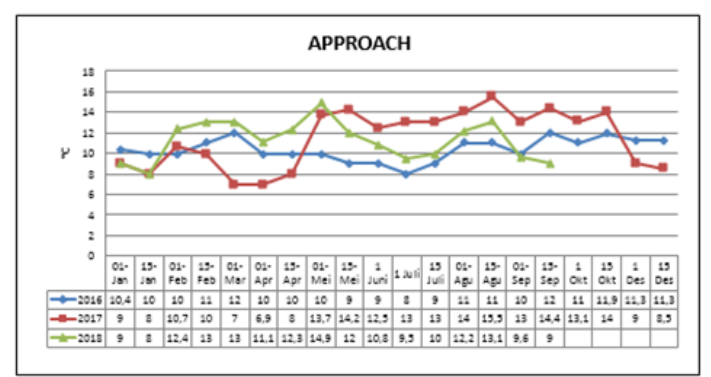

Gambar 4. Grafik Approach

Jika dilihat pada gambar 4.2 dapat disimpulkan Dari tahun 2016 sampai bulan maret 2018 sudut pada fan cooling tower unit 5 memiliki nilai $8,13^{\circ}$ setelah bulan maret dirubah sudutnya menjadi $7,50^{\circ}$ dan rata-rata nilai approach pada pahun 2016 sebesar 11,34 dan pada tahun 2017 sebesar 11,27 dan pada tahun 2018 sebesar 10,8

\section{Efisiensi}

Nilai efisiensi merupakan perbandingan antara range dan range ideal (dalam persentase), yaitu perbedaan antara temperatur masuk air pendingin dan temperatur wet bulb ambien, atau dengan kata lain 
adalah $=$ Range $/$ (Range + Approach). cooling tower taersaji pada gambar 5

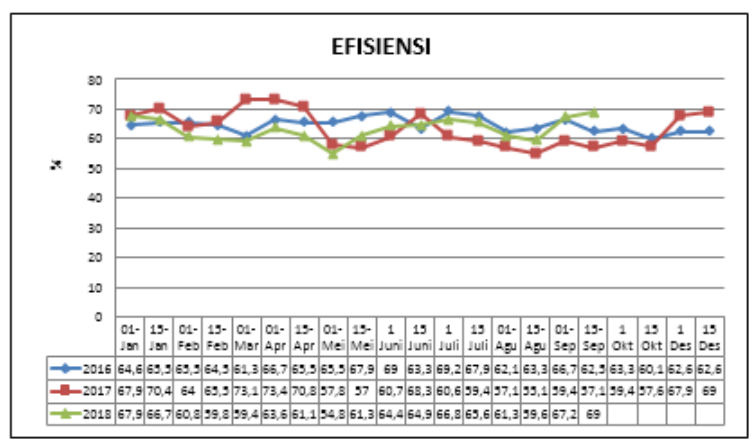

Gambar 5. Grafik Efisiensi

Dari tahun 2016 sampai bulan maret 2018 sudut pada fan cooling tower unit 5 memiliki nilai $8,13^{\circ}$ setelah bulan maret dirubah sudutnya menjadi $7,50^{\circ}$ dan rata-rata nilai efisiensi pada pahun 2016 sebesar 70,67\% dan pada tahun 2017 sebesar 68,13\% dan pada tahun 2018 sebesar 72,27\%.

\section{Evaporation Loss}

Evaporation loss adalah menghitung jumlah air yang menguap akibat dari pengaruh tempetarure. Secara teoritis untuk setiap temperature sebesar $60 \mathrm{C}$ disepanjang menara pendingin , maka sekitar 0,85 \% dari resirkulasi air akan terevaporasi.dari hasil perhitungan diperoleh dari tahun 2016 sampai bulan maret 2018 sudut pada fan cooling tower unit 5 memiliki nilai $8,13^{\circ}$ setelah bulan maret dirubah sudutnya menjadi $7,50^{\circ}$ dan rata-rata nilai evaporation loss pada pahun 2016 sebesar 337,53 $\mathrm{m}^{3} / \mathrm{jam}$ dan pada tahun 2017 sebesar 357,67 m³/jam dan pada tahun 2018 sebesar 348,70 m³/jam

\section{Drift Loss}

Nilai drift loss dari cooling tower sebagaimana diketahui dari tabel spesifikasi sebesar $0,05 \%$ dari sirkulasi air yang masuk kedalam cooling tower. Sehingga batas drift loss yang diperbolehkan dari masing - masing data yang diamati. Nilai Drift Loss dari tahun 2016 sampai tahun 2018 mengalami perubahan fluktuatif yang disebabkan debit yang masuk dari kondesor menuju cooling tower selalu berubah-ubah. . Dengan sudut fan $8,13^{\circ}$ setelah bulan maret dirubah sudutnya menjadi $7,50^{\circ}$ dan rata-rata nilai drift loss pada pahun 2016 sebesar 648,04 m³/jam dan pada tahun 2017 sebesar 613,52 m³jam dan pada tahun 2018 sebesar $580,20 \mathrm{~m}^{3} / \mathrm{jam}$

\section{Windage Loss}

Windage loss adalah kerugian penguapan akibat adanya angin disekeliling menara pendingin.Nilai Windage loss dari tahun 2016 sampai tahun 2018 mengalami perubahan fluktuatif yang disebabkan debit yang masuk dari kondesor menuju cooling tower selalu berubah-ubah. Dari hasil penelitian nilai windage loss dari tahun 2016 sampai bulan maret 2018 sudut pada fan cooling tower unit 5 memiliki nilai 8,13 ${ }^{\circ}$ setelah bulan maret dirubah sudutnya menjadi $7,50^{\circ}$ dan rata-rata nilai windage loss pada pahun 2016 sebesar 2592,19 $\mathrm{m}^{3} / \mathrm{jam}$ dan pada tahun 2017 sebesar 2454,10 m³/jam dan pada tahun 2018 sebesar 2374,71 m³/jam

\section{Make up water}

Dari hasil penelitian nilai make up water dapat dilihat dalam sajian grafik 6 . Nilai make up water dipengaruhi oleh evaporatrion loss, drift loss, windage loss yang selalu berubah ubah

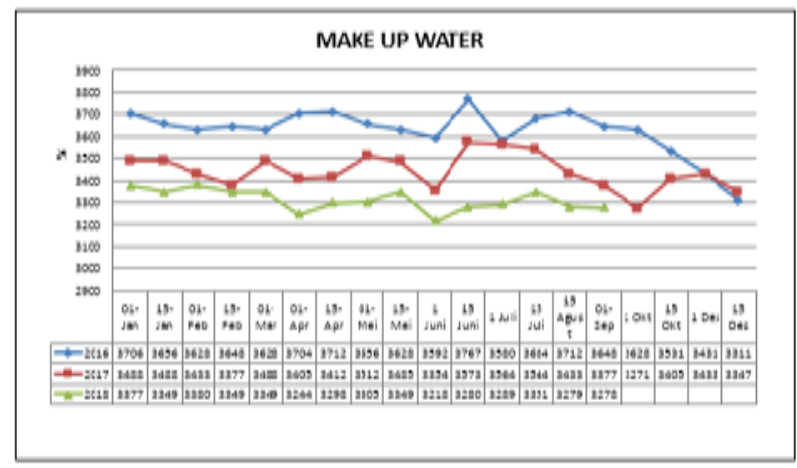

Gambar 6 Grafik make up water

Dengan perubahan sudut $7,50^{\circ}$ dan rata-rata nilai Make Up Water pada pahun 2016 sebesar 3623,56 m³/jam dan pada tahun 2017 sebesar 3441,47 $\mathrm{m}^{3} / \mathrm{jam}$ dan pada tahun 2018 sebesar $3312,94 \mathrm{~m}^{3} / \mathrm{jam}$

\section{SIMPULAN}

Dari hasil analisis dapat disimpulkan beberapa hal diantaranya:

1. Perubahan sudut fan cooling tower unit 1 memiliki nilai $7,83^{\circ}$, unit 2 memiliki nilai $7,97^{\circ}$, unit 3 memiliki nilai $7,83^{\circ}$, unit 4 memiliki nilai $8,13^{\circ}$, unit 5 memiliki nilai $8,18^{\circ}$, setelah bulan maret dirubah sudutnya menjadi unit 1 memiliki nilai $7,83^{\circ}$, unit 2 memiliki nilai $7,50^{\circ}$, unit 3 memiliki nilai $7,50^{\circ}$, unit 4 memiliki nilai $8,13^{\circ}$, unit 5 memiliki nilai $7,50^{\circ}$ dari perubahan sudut mempengaruhi nilai performance, efisiensi, dan kerugian dari aliran menuju cooling tower.

2. Nilai performance dari tahun 2016 sampai 2018 memiliki nilai range tahun 2016 sebesar $11,34^{\circ} \mathrm{C}$, tahun 2017 sebesar $11,27^{\circ} \mathrm{C}$, tahun 2018 sebesar $10,80^{\circ} \mathrm{C}$

3. Nilai performance memiliki nilai rata-rata approach tahun 2016 sebesar $19,085^{\circ} \mathrm{C}$, tahun 2017 sebesar $19,06^{\circ} \mathrm{C}$, tahun 2018 sebesar $19,10^{\circ} \mathrm{C}$

4. Nilai rata-rata efisiensi pada tahun 2016 sebesar 70,67\%, tahun 2017 sebesar 68,13\%, tahun 2018 sebesar 72,27\% . Nilai rata-rata 
evaporation loss pada pahun 2016 sebesar 377,53 m³/jam dan pada tahun 2017 sebesar 357,67 $\mathrm{m}^{3} / \mathrm{jam}$ dan pada tahun 2018 sebesar $348,70 \mathrm{~m}^{3} / \mathrm{jam}$.

5. Nilai kerugian dari tahun 2016 sampai 2018 memiliki nilai rata-rata drift loss pada pahun 2016 sebesar 648,04 m³/jam dan pada tahun 2017 sebesar 613,52 $\mathrm{m}^{3} / \mathrm{jam}$ dan pada tahun 2018 sebesar 580,20 m³/jam .Dilihat dari rata-rata nilai drift loss pada tahun 2016 sampai tahun 2018 perubahannya tidak begitu signifikan tetapi mempengaruhi performance dari cooling tower

6. Nilai kerugian dari tahun 2016 sampai 2018 memiliki nilai rata-rata windage loss pada pahun 2016 sebesar 2592,19 $\mathrm{m}^{3} / \mathrm{jam}$ dan pada tahun 2017 sebesar 2454,10 m3/jam dan pada tahun 2018 sebesar $2374,71 \mathrm{~m}^{3} / \mathrm{jam}$.

7. Nilai kerugian dari tahun 2016 sampai 2018 memiliki nilai rata-rata Make Up Water pada pahun 2016 sebesar 3623,56 m³/jam dan pada tahun 2017 sebesar 3441,47 m³/jam dan pada tahun 2018 sebesar 3312,94 m³/jam.

\section{DAFTAR PUSTAKA}

American society of Heating Refrigeration and Air Conditioning Engineers. ASHRAE Handbook. 4th Edition. 2001

ASHRAE, ASHRAE Handbook 2007.HVAC Application Chapter 3. SI Edition, Atlanta:published by the American Society of Heating, Refrigerating, and Air Conditioning Engineers, Inc.

Apriliana, Dwi. 2018. "Perbandingan Efisiensi Cooling Tower Unit 1 \& 2 Pembangkit Listrik Tenaga Panas Bumi Pt Indonesia Power Upjp Kamojang”. Jakarta : Universitas Muhammadiyah Prof.DR Hamka.

Elvani, Sulistya. 2017. "Maintenance Pada Cooling Tower Di PT. Indonesia Power UPJP Kamojang”. Bandung : Politeknik Negeri Bandung.

Jaber H, Webb RL. 1989. "Design of Cooling Tower by Effectiveness-NTU Method”. ASME J Heat Transf. 43 pp

John C Hensley. 2006. Cooling tower Fundamentals. SPX Cooling Technologies. Kansas. USA

Trika, Restu. 2016. "Prosedur Pemeliharaan dan Perbaikan Cooling Tower di PT. Indonesia Power UPJP Kamojang”. Bandung : Universitas Pasundan Bandung.

Mitsubishi Heavy Industry, Manual Design of Unit 2\&3 Kamojang Geothermal Powerplant.

Departemen Pertambangan dan Energi,(1988), Proyek PLTP Kamojang Unit 2\&3 (2 x 55 MW), Jakarta.
Maintenance Manual CM-21 Kamojang Unit 2 dan 3.

Maintenance Manual Cooling TowerKamojang Unit 2 dan 3.

Performace Curve Report Fan Cooling Tower Kamojang Unit 2 dan 3. 